\title{
USO DE MAPAS MENTAIS PARA AVALIAÇÃO DE IMPACTOS AMBIENTAIS EM AMBIENTE URBANO.
}

\author{
Armando Brito da Frota Filho ${ }^{(\mathrm{a})}$, Tatiana Leite Marão ${ }^{(\mathrm{b})}$ \\ ${ }^{(a)}$ Doutorando do Programa de Pós-graduação em Geografia - UFRJ, e-mail: armandofrota.filho@ @mail.com \\ (b)Professora de ciências e biologia da SEMED-Manaus e SEDUC-AM, e-mail: tatianamarão@ hotmail.com
}

Eixo: GEOGRAFIA FÍSICA: CURRÍCULO, FORMAÇÃO E PRÁTICAS DE ENSINO.

\section{Resumo}

O estudo da questão ambiental é algo deveras complicado, pois há uma dificuldade real entre a apreensão dos conceitos explanados em sala e sua correlação com os demais conhecimentos escolares e o cotidiano dos alunos, afim de facilitar o processo ensino-aprendizagem dessa questão escolheu-se fazer um trabalho voltado para a avaliação dos impactos ambientais que os estudantes estão acostumados a presenciar no seu cotidiano, de forma que eles conseguissem relacionar o conteúdo de sala com a vida foram dela. Os resultados foram satisfatórios, visto que os conceitos foram apreendidos e postos em prática, além dos alunos terem se tornados vetores de sensibilização contra os impactos ambientais deflagrados por familiares e vizinhos.

Palavras-chave: Impactos ambientais - estudo do meio - mapas mentais - ambiente - geografia física

\section{Introdução}

A muito se discute a falta de correlação entre a teoria e os conceitos explicados em sala de aula e sua real e efetiva prática fora dela, e mais precisamente no cotidiano do aluno, essa dificuldade se apresenta de forma mais intensa quando trata dos conteúdos voltados à questão ambiental, escopo da Geografia Física, uma vez que os alunos entendem o conceito, de forma abstrata e não prárica, assim não conseguindo aplica-lo a sua vida.

Essa temática ganha outra dimensão visto que as políticas voltadas à sensibilização da crise ambiental demandam cada vez mais novos enfoques integradores (BIGOTO, 2008), fazendo-se necessário uma nova forma de abordar temas relacionados ao ambiente de forma que o processo de ensinoaprendizagem seja efetivo e significativo.

Mas para trabalhar a questão ambiental, que por si só é bastante ampla, é preciso o conjunto de diversas disciplinas (MENDONÇA, 2002; LATUF, 2007; SILVA,2010), e que as mesmas dialoguem, pois segundo Pontuschka e Paganelli (2007) o ensino-aprendizagem para que sejam realmente significativos, os diferentes saberes devem interagir para criar um novo saber. 
Á medida que se valoriza o conhecimento prévio que os alunos possuem, pois os mesmos não chegam a escola como páginas em branco, e cada um deles apresente uma carga de conhecimento prévio, conhecimento empírico e inerente a cada um de nós, assim como a forma de observar os mundo ao seu redor. Com base nessa necessidade, o presente artigo tem como objetivo: compreender os impactos ambientais (naturais e sociais) e suas relações com o cotidiano do aluno.

\section{Metodologia}

A fim de alcançar o objetivo de compreender os impactos ambientais e suas relações com o cotidiano do aluno, utilizou-se a combinação de duas metodologias, o estudo do meio (PONTUSCHKA, PAGANELLI e CACETE, 2009) e os mapas mentais (NOGUEIRA, 2002) (SILVA, 2002).

O estudo do meio consiste em usar um local conhecido pelos alunos, que pode ser desde o seu trajeto da casa a escola ou mesmo o entorno desta última, tal metodologia implica em utilizar as observações, conhecimento e mesmo ponderações que aluno possua sobre a área (PONTUSCHKA, PAGANELLI e CACETE, 2009).

É nesse sentido que projetos de investigação no ensino, propiciam ao aluno o contato direto com o meio próximo em que vive, este tipo estudo faz com que os estudantes tenham compreensão dos conceitos e por sua vez consigam através de trabalhos de campo a utilização conceitual (CAVALCANTI, 2002).

Compiani (2007) e Vega (2007) apontam que este tipo de metodologia por fazer a relação entre a teoria e a práxis atua como agente fomentador para o desenvolvimento do saber, pois no trabalho de campo o aluno correlaciona os conhecimentos adquiridos em sala e sua apresentação no cotidiano. Demo (2004) corrobora ao apontar que é através de pesquisas, principalmente as que vão além da mera pesquisa bibliográfica, a qual envolva os interesses dos alunos, e que apresente o dinamismo de pesquisador-objeto desenvolvendo melhor o aprendizado.

Os mapas mentais vêm com a finalidade de representar cartograficamente estas observações e percepções dos alunos, pois "os mapas mentais são representações construídas inicialmente tomando por base a percepção dos lugares vividos, vivenciados, portanto partem de uma dada realidade" (NOGUEIRA, 2002), fazendo com que o aluno trabalhe questões de lateralidade, horizontalidade, escala e representação, relacionando com técnicas cartográficas ensinadas em sala de aula.

O trabalho foi realizado com 02 turmas de sétimo ano do Ensino Fundamental II, a escola é localizada na Zona Leste da cidade de Manaus apresenta-se como uma região de ocupação recente, cujos bairros são resultado da expansão da malha urbana que ocorreu sem o devido planejamento, desconsiderando aspectos naturais. Por tratar-se de ocupação espontânea, alguns dos bairros dessa área não são completamente asfaltados, não apresentando rede de saneamento básico ou coleta de lixo. 
As duas turmas de sétimo ano totalizaram 65 alunos, com os quais inicialmente houve aulas expositivas sobre o tema de impactos ambientais em cidades, explicando-se conceitos e exemplificando-os, e ao fim da aula, foi proposta uma atividade na qual os alunos deveriam registrar tudo aquilo que eles considerassem um impacto ambiental na vizinhança deles. Na aula seguinte, os alunos entregaram os mapas mentais com as suas observações e novamente foi debatido em sala o que seriam os impactos, mas neste momento debateu-se o papel do aluno e da sociedade na causa desse impacto, assim como suas consequências no seu cotidiano.

\section{Resultados e discussões}

Como dito anteriormente, a pesquisa contou com 65 alunos, contudo quatro alunos mesmo após a explicação não conseguiram alcançar o objetivo, enquanto outros descreveram mais de um impacto ambiental na vizinhança onde moram. Dessa forma, foram registrados 89 impactos ambientais. $\mathrm{O}$ quadro 01 e gráfico 01 mostram os temas que foram retratados e a quantidade de vezes que foram citados.

Quadro 01: Temas e quantidade de impactos registrados pelos alunos.

\begin{tabular}{|l|c|c|}
\hline \multicolumn{1}{|c|}{ Temas } & Quantidade & Porcen. (\%) \\
\hline Resíduos Sólidos na rua & 37 & 40 \\
\hline Resíduos Sólidos no rio & 16 & 17 \\
\hline Desmatamento & 08 & 09 \\
\hline Poluição atmosférica & 08 & 09 \\
\hline Queimadas & 06 & 07 \\
\hline Esgoto no rio & 04 & 04 \\
\hline Esgoto a céu aberto & 02 & 02 \\
\hline Buracos na rua & 05 & 06 \\
\hline Queima de resíduos sólidos & 04 & 04 \\
\hline Alagamentos & 01 & 01 \\
\hline Poluição Sonora & 01 & 01 \\
\hline Total & 89 & 100 \\
\hline
\end{tabular}

Org.: Armando Brito da Frota Filho, 2016. 


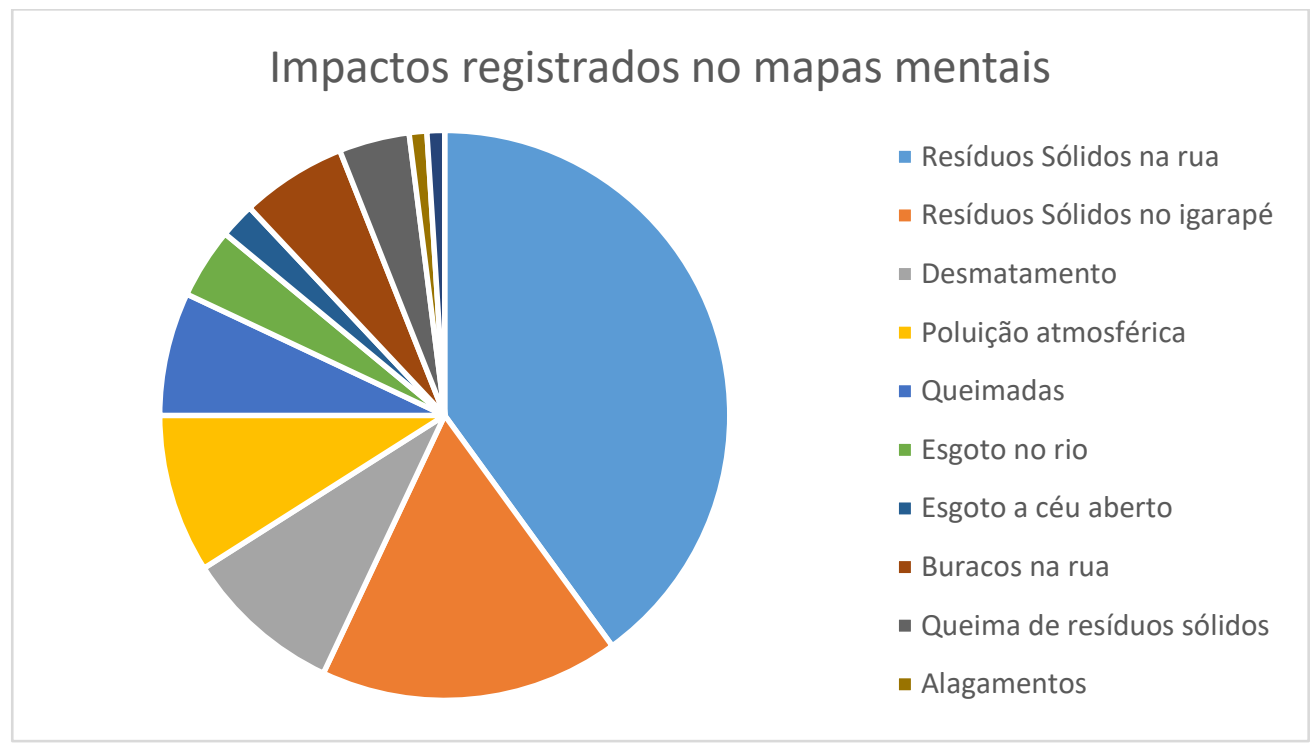

Gráfico 01: Impactos registrados pelos alunos. Org: Armando Brito da Frota Filho, 2016.

Em ambiente urbano os impactos ambientais são palpáveis aos alunos, dentre os que mais chamam atenção dos alunos está os "resíduos sólidos na rua", onde $40 \%$ dos registros realizados correspondem a esse tema.

Outro tema, recorrente foram os "resíduos sólidos nos rios" (17\%) e o esgoto direcionado ao rio (04\%), esse fato mostra como a poluição dos cursos hídricos é intensa, a figura 01 mostra 04 mapas mentais que exemplificam estes dois temas, nos quais os materiais que mais aparecem nos registros são: garrafas PET, latas e pneus.
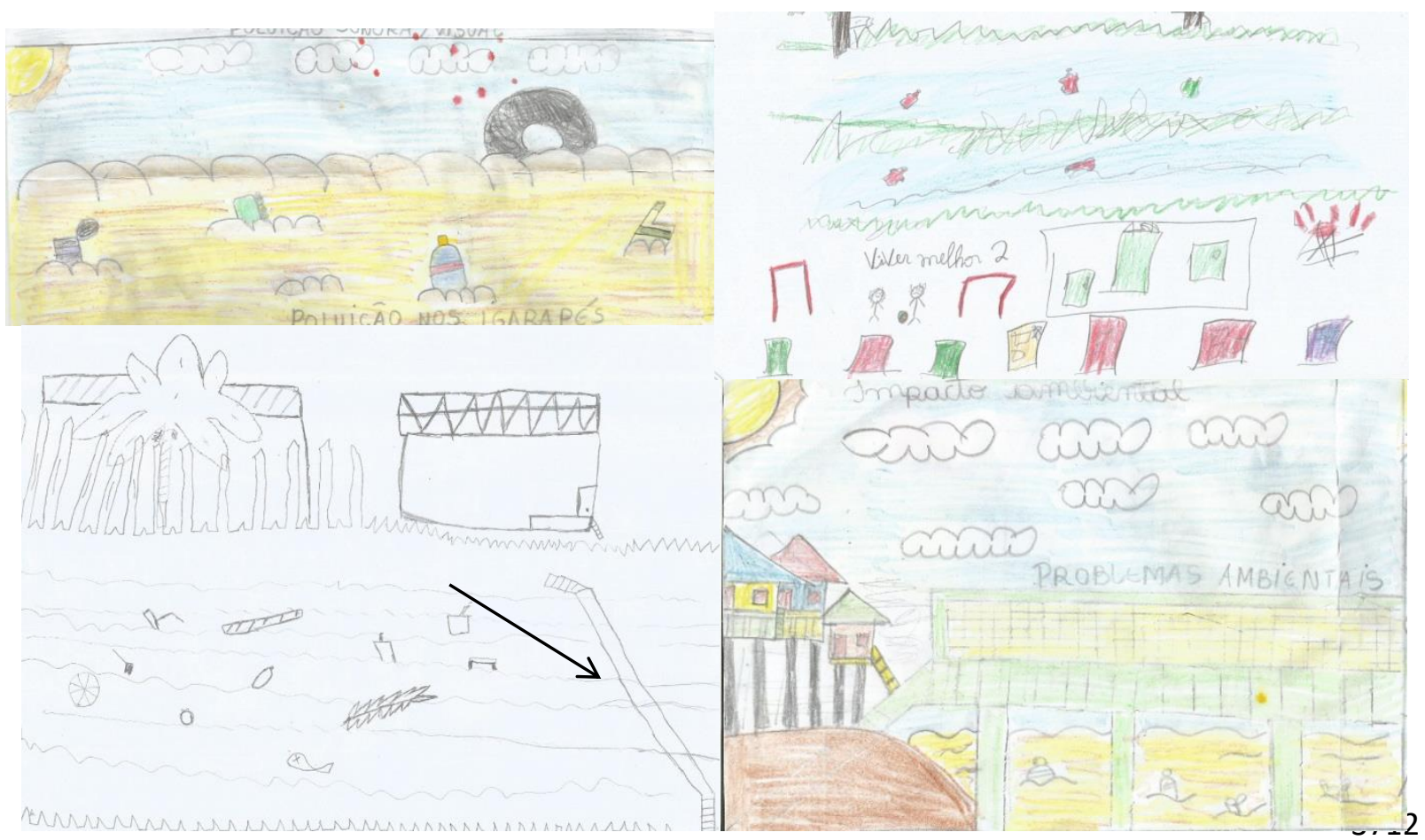
Figura 01: Mapas mentais representando os resíduos sólidos e encanamento de esgoto direcionado para o canal fluvial. Seta preta indica o encanamento direcionado para o curso d'água. Org: Armando Brito da Frota Filho, 2016.

A degradação do solo foi outro tema recorrente, no qual o desmatamento (09\%) e as queimadas $(07 \%)$ tendem a desencadear e acelerar os processos erosivos, algo que é recorrente na parte da cidade, fato este autenticado por estudos de Vieira (2008) e Frota Filho (2016) que pontuaram diversas voçorocas.

Em alguns casos, estas feições erosivas estão próximas a residências, criando áreas de risco, algo que foi pontuado por um aluno em seu mapa mental (FIGURA 02), ao descrever o registro o aluno explicou que a casa está localizada em um topo de encosta e que há um "buraco" que está se aproximando da casa. Assim, é possível inferir que o aluno estava falando de uma voçoroca que crescia em direção a casa.

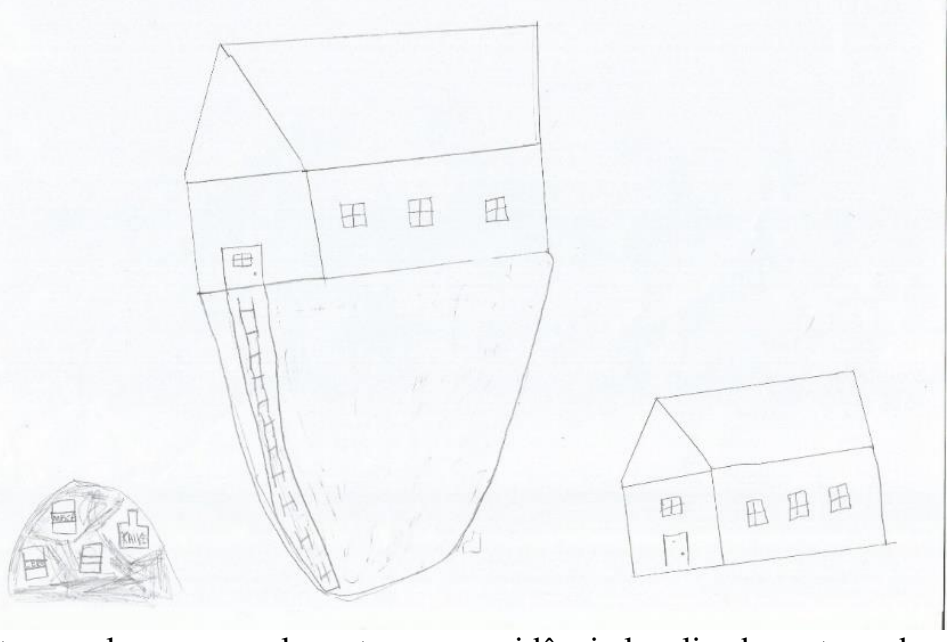

Figura 02: Registro feito por aluno, no qual mostra uma residência localizada no topo de uma encosta e com um "buraco" (voçoroca) próximo.

Todos os pontos levantados pelos alunos tem relação direta com a falta de infraestrutura que a região possui como o esgoto a céu aberto/direcionado ao rio e buracos na rua (06\%) (FIGURA 03a), ou a queima de resíduos sólidos (04\%) como consequência da falta de coleta de lixo (FIGURA 03b), ou os alagamentos $(01 \%)$ que ocorrem pois os bueiros não conseguem escoar a água devido a quantidade lixo acumulado (FIGURA 03c).

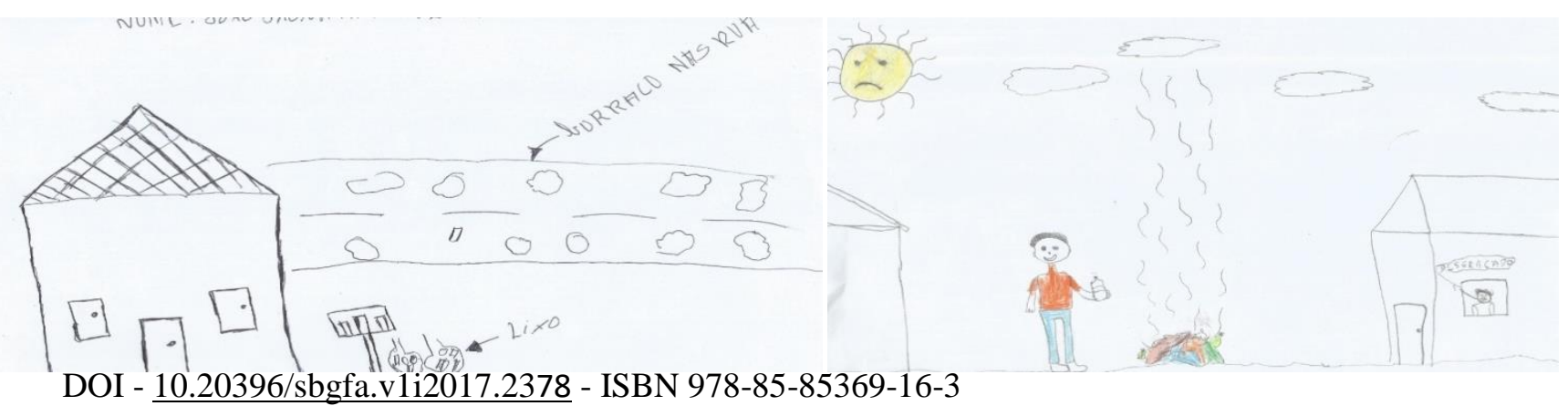




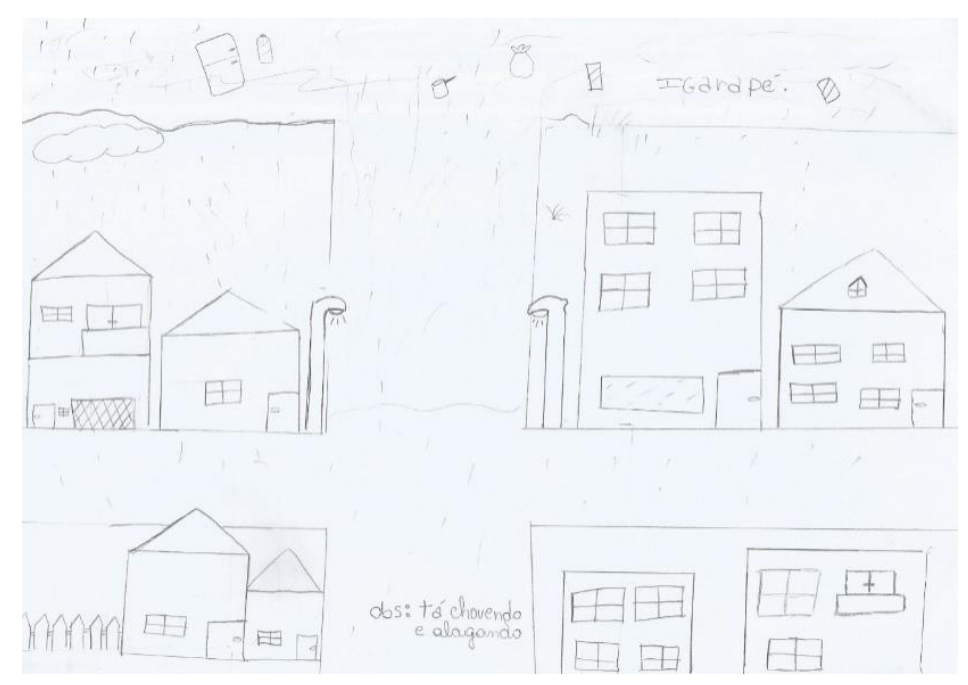

Figura 03:a) Registro de buracos nas ruas; b) Registro de "lixo" acumulado nas vias públicas; c) Registro de alagamentos.

\section{Considerações finais}

A proposta de trabalho realizada com os alunos tinha objetivo dar as ferramentas (conceitos) para melhor compreender os impactos ambientais, desde de suas causas até suas consequências, além da sua relação com o cotidiano de cada um. E nessa perspectiva que primeiramente devem entender a questão, interpretando o seu meio, ou seja, a realidade local para então extrapolar para a realidade global.

Como a pesquisa envolveu a realidade dos alunos e consequentemente um interesse deles, o resultado foi o empenhos dos alunos e maior apreensão do conteúdo explanado, no qual os discente mostram como relacionar os conceitos e correlacionando com outros tópicos da ciência geográfica, assim como de outras disciplinas e suas experiências de cotidiano.

O que gerou a sensibilização em relação aos impactos ambientais, visto que devido a vizinhança, localizada em uma zona menos desenvolvida e com diversos problemas envolvendo coleta de lixo e saneamento básico, muitos dos parentes e vizinhos dos alunos desenvolvem atividades que impactam o meio ambiente. Sendo a mais recorrente a queima dos resíduos domésticos (lixo residencial), e como resultado positivo alguns alunos apontaram que explicaram os efeitos danosos dessa atividade a estas pessoas, transformando-se me vetores da sensibilização quanto aos impactos ambientais. 
Quanto aos pontos negativos da atividade destacam-se basicamente questões de cunho estrutural, como: falta de materiais e mesmo a impossibilidade da realização de um campo coletivo onde os discentes pudessem fazer interações entre eles, observando um mesmo local e debatendo os diversos pontos de vista.

\section{REFERÊNCIAS}

ARMOND, N. B. ; AFONSO, A. E. . Da Geografia Física à Geografia (sócio)Ambiental e seu "retorno" à Geografia: breves reflexões sobre mutações epistemológicas e o campo científico. In: XVI ENG - Encontro Nacional de Geógrafos, 2010, Porto Alegre. Anais do XVI Encontro Nacional de Geógrafos. Porto Alegre: AGB Porto Alegre, 2010.

BIGOTTO, A. C. Educação Ambiental e o desenvolvimento de atividades de ensino na escola pública. Dissertação (Mestrado em Educação) - Faculdade de Educação da USP.2008.

CAVALCANTI, L. S. Geografia e práticas de ensino. Goiânia: Editora Alternativa, 2002. v. 1. 127p

COMPIANI, Maurício. O lugar e as escalas e suas dimensões horizontal e vertical nos trabalhos práticos: implicações para o ensino de ciências e educação ambiental. Ciência e Educação (UNESP), v. 13, p. 29-45, 2007

DEMO, Pedro. Pesquisa Participante - Saber pensar e intervir juntos. Brasília: Liber Livro, 2004. v. 1. 139p .

FROTA FLHO, A.B. Análise da vulnerabilidade erosiva da Bacia Hidrográfica Colônia Antônio Aleixo, Manaus-AM. (Dissertação de mestrado). Manaus-AM: UFAM/ICHL, 2016.

LATUF, M. O. . Geografia Física ou Humana, ou será apenas Geografia?. Formação (Presidente Prudente), v. 1, p. 205-206, 2007.

MENDONÇA, F. Geografia Socioambiental. Terra livre.São Paulo: nº 16, p. 139 - 158, 2002

NOGUEIRA, A.R.B. Mapa Mental: Recurso didático para o estudo do Lugar. In: Pontuschka, Nídia e Oliveira, Ariovaldo. (Org.). Geografia em Perspectiva. 1 ed.São Paulo: Editora Contexto, 2002, v. , p. 125-133.

PONTUSCHKA, N. N. ; PAGANELLI, T. I. ; CACETE, N. H. . Para ensinar e aprender GEOGRAFIA - $3^{\mathrm{a}}$. ed. São Paulo: Cortez, 2009. v. 1000. 383p .

SILVA, Ana Cristina da. Materiais especiais: conceitos, tratamentos e a formação de uma hemeroteca. (Monografia)Natal: UFRN, 2002. 
SILVA, Marcos Antônio da. FONSECA, Selva Guimarães. Ensino de História hoje: errâncias, conquistas e perdas. Revista Brasileira de História (Impresso), v. 30, p. 13-33, 2010.

VEGA, Alfonso García de la. Un Enfoque Innovador En La Didáctica Del Paisaje: Escenario Y Secuencia Geográfica. In: GONZÁLEZ, Rafael De Miguel. TORRES, María Luisa De Lázaro y. GAITE, María Jesús Marrón (Org.) Innovación en la enseñanza de la geografía ante los desafíos sociales y territoriales $1^{\circ}$ ed. Zaragoza, Espanha. 2007

VIEIRA, A.F.G. Desenvolvimento e distribuição de voçorocas em Manaus (AM): principais fatores controladores e impactos urbano-ambientais. (Tese de doutorado). Florianópolis: UFSC/CFH, 2008. 